\title{
VIDEO ANIMASI DUA DIMENSI SEBAGAI MEDIA PROMOSI
}

\author{
Widya Meli Anggraini ${ }^{1}$, Dadang Priyanto ${ }^{2}$ \\ ${ }^{1}$ Mahasiswa, ${ }^{2}$ Dosen STMIK Bumigora; Jurusan Teknik Informatika \\ Jl. Ismail Marzuki, Kota Mataram, Nusa Tenggara Barat. \\ e-mail: ${ }^{1}$ widyaanggraini78@gmail.com, ${ }^{2}$ dadang_tesis@yahoo.com
}

\begin{abstract}
ABSTRAK
Sekolah Menengah Kejuruan Negeri Tiga (SMKN 3) Sumbawa Besar merupakan sekolah yang bergerak dibidang pendidikan kejuruan pada jenjang pendidikan menengah sebagai lanjutan dari hasil belajar yang diakui sama/setara SMP/MTS. Sekolah ini memiliki beberapa jurusan diantaranya Teknik Komputer dan Jaringan (TKJ), Busana Butik(BB), Administrasi Perkantoran(AP), dan Akuntansi(AK). Perkembangan teknologi yang semakin pesat Sekolah Menengah Kejuruan Negeri Tiga (SMKN 3) Sumbawa Besar membutuhkan sarana publikasi yang mampu menarik minat calon siswa baru dan wali murid. Penulis membuat rumusan masalah yaitu bagaimana membuat video animasi dua dimensi sebagai media promosi agar menarik minat calon siswa dan wali murid dengan menggunakan software yang mendukung pembuatan video. Tujuan penulisan skripsi ini adalah membuat video animasi dua dimensi sebagai media promosi untuk menarik minat dan mudah dipahami calon siswa dan wali murid dalam melakukan publikasi. Dalam pembuatan Video Animasi Dua Dimensi Sebagai Media Promsi SMKN 3 Sumbawa Besar menggunakan Metode pengembangan multimedia Luther Sutopo. Adapun tahapannya adalah Concept, Design, Material collecting, Assembly, Testing, Distribution.
\end{abstract}

Kata Kunci: Multimedia, Video Animasi, Media Promosi

\begin{abstract}
Three Vocational High School (SMK 3) Sumbawa Besar is a school in the field of vocational education in secondary education as a continuation of the learning outcomes recognized same / similar SMP / MTS. The school has several departments including Computer Engineering and Networks (TKJ), Clothing Boutique (BB), Administrative (AP), and Accounting (AK). The development of increasingly rapid technological Three Vocational High School (SMK 3 ) Sumbawa Besar requires publications are able to attract the interest of potential new students and parents. The author makes the formulation of the problem is how to make two-dimensional animation video as a media campaign in order to attract prospective students and parents to use software that supports video creation. The purpose of this thesis is to create two-dimensional animation video as a media campaign to attract and easy to understand prospective students and parents in making the publication. In the manufacture of Video Animation TwoDimensional As Media Promsi SMK 3 Sumbawa Besar using multimedia development method Luther Sutopo. The stages are Concept, Design, Material collecting, Assembly, Testing, Distribution.
\end{abstract}

Keywords : Multimedia, Video Animation, Media Promotions

\section{PENDAHULUAN}

Perkembangan ilmu pengetahuan dan teknologi dari tahun ke tahun semakin pesat. Dengan perkembangan ilmu teknologi ini membantu manusia memasuki era global yang tak terbatas dengan berbagai macam bidang teknologi. Teknologi juga memiliki peran besar terhadap perkembangan ilmu pengetahuan pada sekolah-sekolah. Salah satu teknologi yang memberikan informasi dan sangat marak sekali digunakan masyarakat umum adalah teknologi multimedia dibidang animasi 2 dimensi (2D). Teknologi multimedia di bidang animasi 2 dimensi (2D) merupakan salah satu cara mempermudah suatu penyampaian informasi dalam bentuk visual maupun audio visual.[1] 
Perkembangan teknologi yang semakin pesat

SMKN 3 Sumbawa Besar membutuhkan sarana publikasi yang mampu menarik minat calon siswa baru dan wali murid. SMKN 3 Sumbawa Besar mempunyai fasilitas untuk sarana promosi dan menyampaikan informasi yaitu dengan menggunakan media cetak lokal, media sosial, media online "kabarsamawa.com" dan brosur yang disebar ke sekolah-sekolah.

Permasalahan yang dihadapi oleh pihak sekolah dalam melakukan promosi kepada calon siswa baru, berdasarkan hasil wawancara adalah wali murid dan siswa tidak semua aktif dalam media sosial dan untuk penyebaran brosur ke sekolah-sekolah bermasalah pada waktu bagi pihak SMKN 3 Sumbawa Besar untuk mengunjungi sekolah-sekolah SMP/MTS hanya bisa dilakukan pada saat imtaq. Mekanisme pendistribusian terkait dengan anggaran dana untuk sarana promosi berkisar sampai 10juta pertahun. Kemudian untuk media cetak dan brosur diperkirakan 3-4juta.

Berdasarkan permasalahan tersebut penulis akan membuat video animasi sebagai media promosi. Karena dengan menggunakan media cetak lokal, brosur, media sosial, dan media Effect Cs6 dan Adobe Premiere Pro Cs6, dan durasi video animasi ini 1:48 detik.

\section{METODOLOGI}

1. Metode Pengumpulan Data

\section{Wanwancara}

Penulis melakukan interview dengan wakil kepala sekolah SMKN 3 Sumbawa Besar untuk mengetahui kendala apa yang online sebagai sarana publikasi belum maksimal dalam mempromosikan sekolah karena belum tentu semua siswa dan wali murid aktif dalam media sosial dan aktif dalam membaca. Maka dengan pembuatan sebuah video animasi dua dimensi sebagai sarana untuk mempublikasikan sekolah juga meningkatkan media promosi sekolah untuk bersaing dengan sekolah lain dibidang pendidikan.

Berdasarkan identifikasi masalah penulis membuat rumusan masalah yaitu, "Bagaimana membuat video animasi dua dimensi sebagai media promosi agar menarik minat calon siswa dan wali murid dengan menggunakan software yang mendukung pembuatan video animasi?"

Adapun batasan masalah dari video animasi dua dimensi sebagai media promosi adalah pengambilan data dilakukan di SMKN 3

Sumbawa Besar, video ditambahkan konten animasi dua dimensi mempromosikan tentang jurusan di SMKN 3 Sumbawa Besar, penelitian menghasilkan video animasi dua dimensi sebagai media promosi, video animasi ini ditayangkan pada televisi lokal dan dapat digunakan untuk mengisi even - even sekolah, pembuatan video promosi menggunakan software Adobe After dihadapi pada saat melakukan promosi, dengan hasil sebagai berikut :

a. Dari hasil wawancara penulis adalah pentingnya media promosi berupa visual untuk mempermudah calon siswa memahami maksud dari informasi yang disampaikan.

b. Dari hasil wawancara penulis bahwa kendala yang dihadapi pada saat promosi dan menyampaikan informasi adalah 
keterbatasan waktu untuk mengunjungi sekolah dan hanya dilakukan pada saat Imtaq.

c. Dari hasil wawancara penulis bahwa ruang lingkup penggunaan sarana promosi pada sasaran adalah dengan mengunjungi sekolah di kecamatan terdekat dengan membagikan brosur.

d. Dari hasil wawancara penulis bahwa dengan menggunakan sarana promosi sebelumnya mengeluarkan biaya yang cukup mahal untuk mencetak brosur setiap tahun.

\section{Studi Pustaka}

Studi pustaka dilakukan untuk menentukan apa saja informasi yang akan dicantumkan dalam video animasi ini. Penulis mengambil data dari SMKN 3 Sumbawa Besar dan dari buku buletin sekolah.

\section{Metode Pengembang Multimedia}

Dalam pembuatan video animasi dua dimensi sebagai media promosi penulis menggunakan metodologi pengembangan perangkat lunak Luther-Sutopo yang terdiri dari 6 tahapan :[5]

\section{$\checkmark$ Concept}

Tahap concept (konsep) adalah tahap untuk menetukan tujuan dan pengguna program (identifikasi audience).

\section{$\checkmark$ Design}

Design (perancangan) adalah tahap membuat spesifikasi mengenai arsitektur program, gaya tampilan dan kebutuhan material/bahan untuk program.

\section{$\checkmark \quad$ Material Collecting}

Material Collecting adalah tahap dimana pengumpulan bahan yang sesuai dengan kebutuhan dilakukan. Tahap ini dapat dikerjakan paralel dengan tahap assembly. Pada beberapa kasus, tahap Material Colecting dan tahap Assembly akan dikerjakan secara lenear tidak paralel.

$\checkmark$ Assembly

Tahap Assembly (pembuatan) adalah tahap dimana semua objek atau bahan multimedia dibuat. Pembuatan aplikasi didasarkan pada tahap design.

\section{Testing}

Dilakukan setelah selesai tahap pembuatan (assembly) dengan menjalankan aplikasi/program dan lihat apakah ada kesalahan atau tidak. Tahap ini disebut juga sebagai tahap pengujian alpha (alpha test) dimana pengujian dilakukan oleh pembuat atau lingkungan pembuatannya sendiri.

\section{$\checkmark$ Distribution}

Tahapan dimana aplikasi disimpan dalam suatu media penyimpanan. Pada tahap ini jika media penyimpanan tidak cukup untuk menampung aplikasi, maka dilakukan kompresi terhadap aplikasi.

\section{a. Rancangan Konsep/Naskah}

Memakai konsep karakter animasi dua dimensi. Konsep ini dipakai karena diharapkan mampu menarik minat siapa saja yang melihatnya, terutama para calon siswa.

Frame 01 : Intro yang menampilkan logo SMKN 3 Sumbawa Besar

Audio : Musik, vocal 
Frame 02 : Menampilkan visi SMKN 3

Sumbawa Besar

$\begin{array}{ll}\text { Audio } & \text { : Musik } \\ \text { Frame 03 } & \text { : Menampilkan Misi SMKN 3 } \\ & \text { Sumbawa Besar } \\ \text { Audio } & \text { : Musik }\end{array}$

Frame 04 : Mencari Jurusan

Audio : Musik, vocal

Frame 05 : Memilih Jurusan

Audio : Musik, vocal

Frame 06 : Jurusan Administrasi perkantoran.

Audio : Musik, vocal

Frame 07 : Video jurusan administrasi perkantoran

Audio : Musik, vocal

Frame 08 : Jurusan Akuntansi

Audio : Musik, vocal

Frame 09 : Video jurusan akuntasi

Audio : Musik, vocal

Frame 10 : Jurusan Teknik Komputer Jaringan

Audio : Musik, vocal

Frame 11 : Video jurusan teknik komuter jaringan

Audio : Musik, vocal

Frame 12 : Jurusan Busana Butik

Audio : Musik, vocal

Frame 13 : Video jurusan busana butik

Audio : Musik, vocal

Frame 14 : Slogan dengan kalimat ajakan

Audio : Musik, vocal

Frame 15 : Penutup yang menampilkan logo sekolah

Audio : Musik, vocal

\section{b. Desain (Design)}

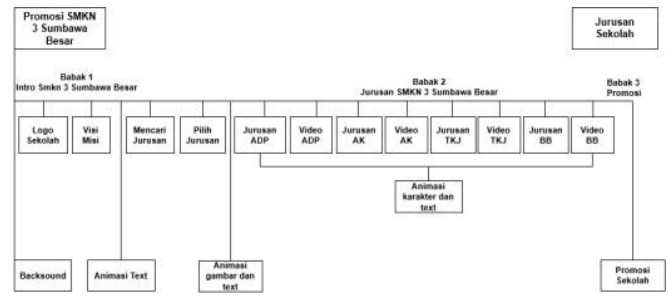

Gambar 1 Diagram Scane

\section{c. Material Colecting}

Tahap ini dilakukan setelah konsep produk telah di buat dan di desain dengan lengkap. Berdasarkan konsep dan desain tersebut dapat diidentifikasi material yang dibutuhkan dalam tahap implementasi. Adapun material yang dibutuhkan adalah:

a. Logo SMKN 3 Sumbawa Besar

b. Visi Misi SMKN 3 Sumbawa Besar

c. Animasi Karakter dari google

d. Backsound audio dari Video

e. Video masing-masing jurusan

Dalam proses pengumpulan data pembuatan Video Animasi Dua Dimensi Sebagai Media Promosi SMKN 3 Sumbawa Besar yang dalam tahap pengumpulan data adalah sebagai berikut :

1. Proses Pengambilan Gambar

Dalam proses pemgambilan gambar membuat Video Animasi SMKN 3 SUMBAWA BESAR menggunakan Camera Sony, yang berlokasi di SMKN 3 Sumbawa Besar.

2. Proses Recording Narasi

Proses Recording Narasi menggunakan SmartPhone Oppo Neo 7 yang akan diedit menggunakan adobe premiere pro cs6. Recording yang dihasilkan berformat Mp3. 


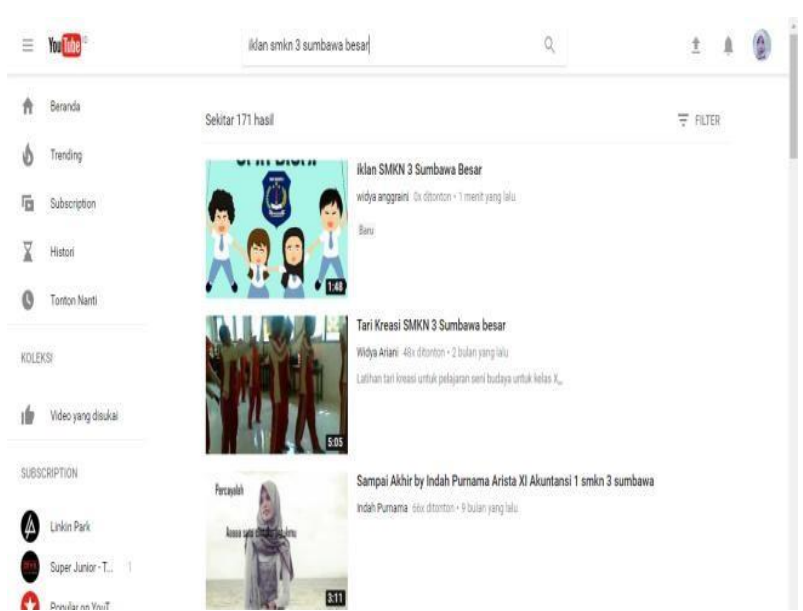

Gambar 13. Distribusi di Youtube

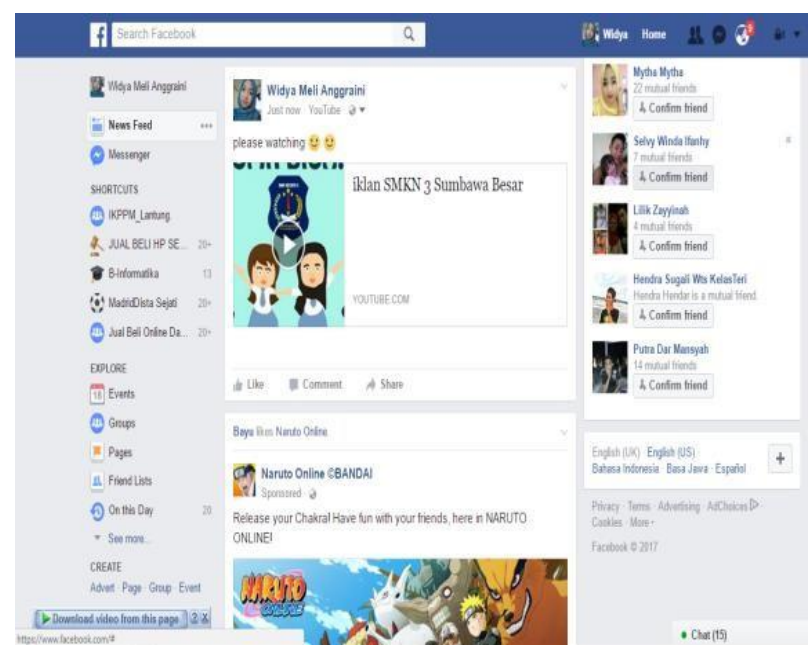

Gambar 14. Distribusi di Facebook
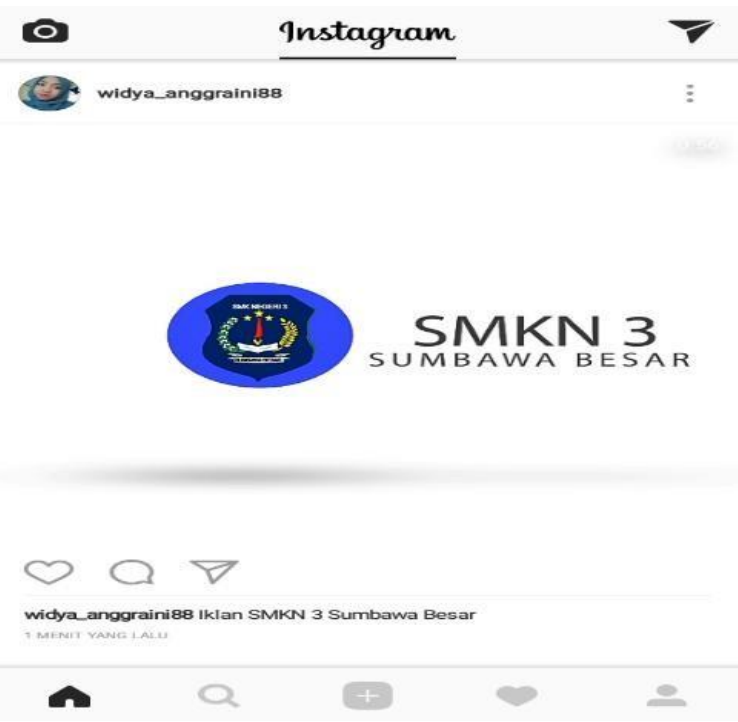

Gambar 15. Distribusi di Instagram
2. Dalam Merancang konsep dari Video Animasi SMKN 3 Sumbawa Besar melibatkan elemen-elemen multimedia yang meliputi video, teks, animasi, gambar dan suara. Pembuatan elemen-elemen tersebut menggunakan software Adobe After Effects CS6 dan Adobe Premiere Pro CS6

\section{HASIL DAN PEMBAHASAN}

\section{Hasil}

Interface video ditampilkan dari hasil pembuatan video animasi dua dimensi sebagai hasil akhir dari video animasi dua dimensi sebagai media promosi SMKN 3 Sumbawa Besar.

\section{a) Intro}

Bagian intro sebagai pembuka awal yang menampilkan logo SMKN 3 Sumbawa Besar.

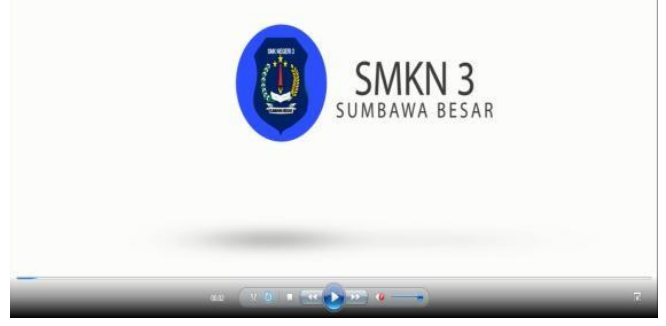

Gambar 2. Interface Intro

\section{b) Visi Misi}

Bagian visi misi sekolah ditampilkan setelah intro yang menjelaskan visi dan misi dari SMKN 3 Sumbawa Besar.

\section{d. Assembly}


Vol.1 No.1 (Mei) 2019, Hal 41-49

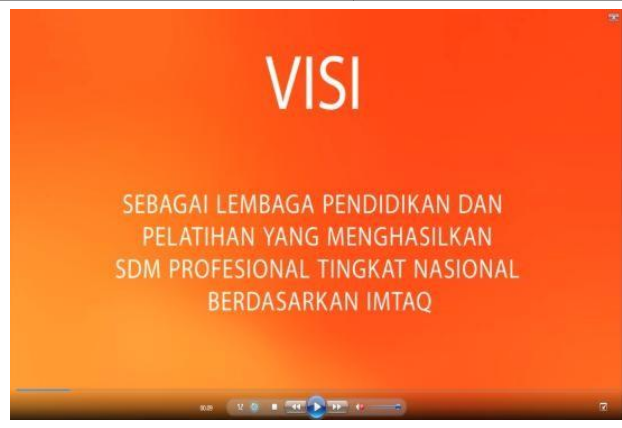

Gambar 3. Interface Visi

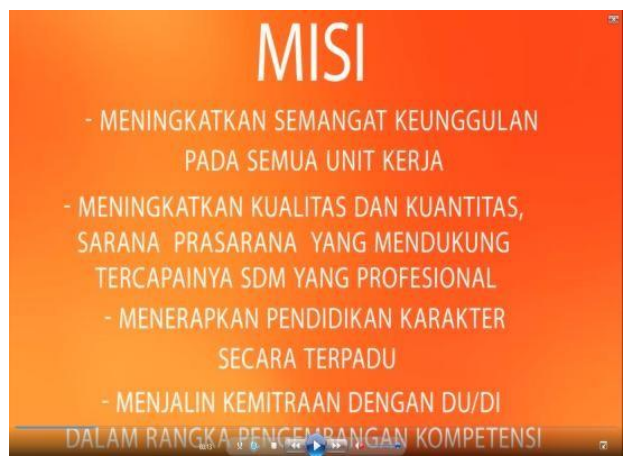

Gambar 4. Interface Misi

\section{c) Mencari Jurusan}

Bagian mencari jurusan adalah bagian yang menggambarkan pencarian jurusan SMKN 3 Sumbawa Besar melalui google.

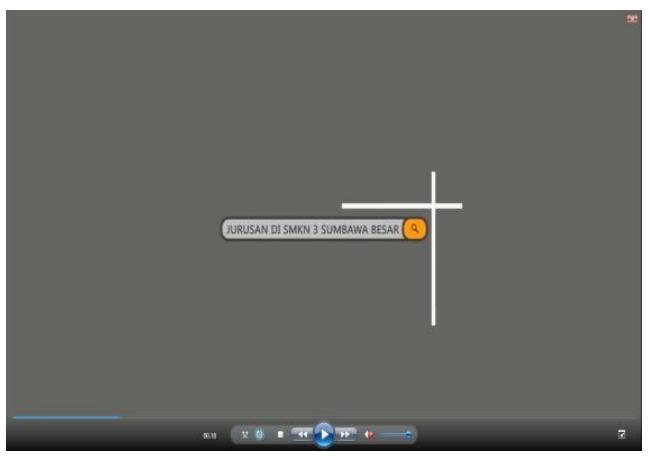

Gambar 5. Interface Mencari Jurusan

\section{d) Memilih Jurusan}

Bagian ini menggambarkan pemilihan jurusan seolah-olah dengan mengklik menu jurusan untuk melihat informasi yang ada dimenu jurusan kemudian akan menampilkan informasi masing-masing jurusan.

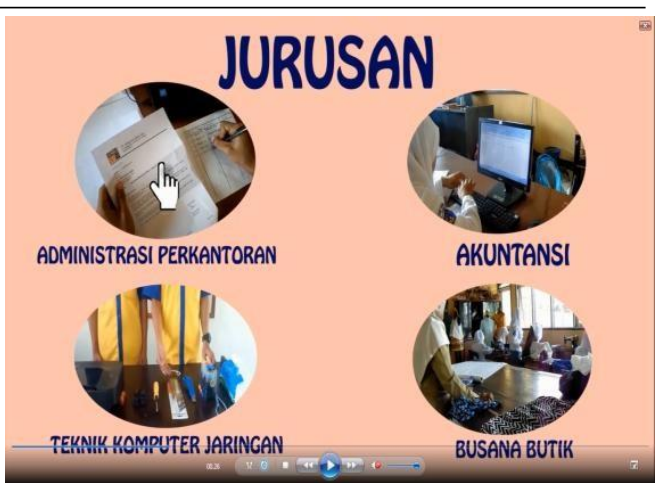

Gambar 6. Interface Memilih Jurusan

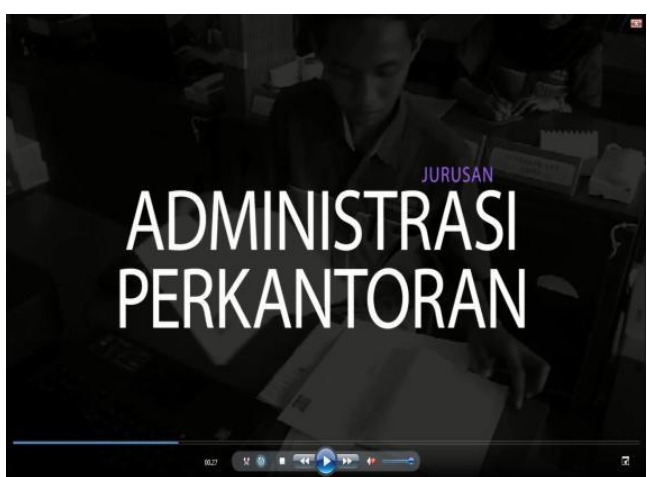

Gambar 7. Interface Intro Jurusan Administrasi Perkantoran

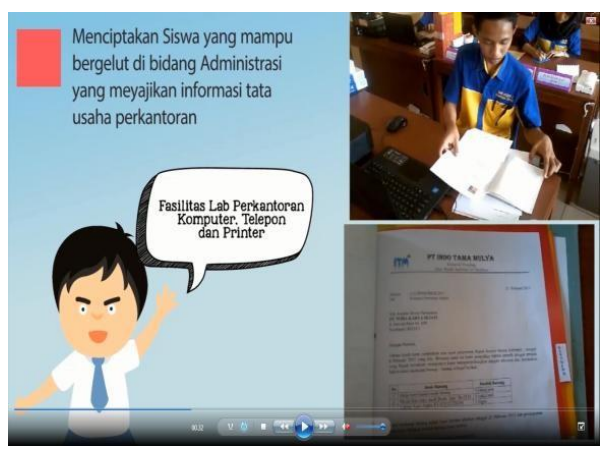

Gambar 8. Interface Jurusan Administrasi Perkantoran

\section{e) Video Jurusan Administrasi Perkantoran}

Video jurusan administrasi perkantoran ditampilkan setelah informasi jurusan perkantoran.

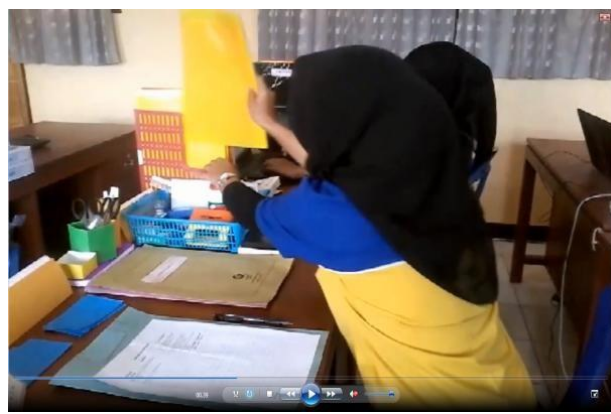


Gambar 9. Interface VideoJurusan Administrasi Perkantoran

\section{f) Ending Video}

Ending video merupakan bagian akhir atau penutup dari video animasi dua dimensi yang berisi slogan ajakan untuk mendaftarkan diri di SMKN 3 Sumbawa Besar dan merupakan bagian promosi dari video.
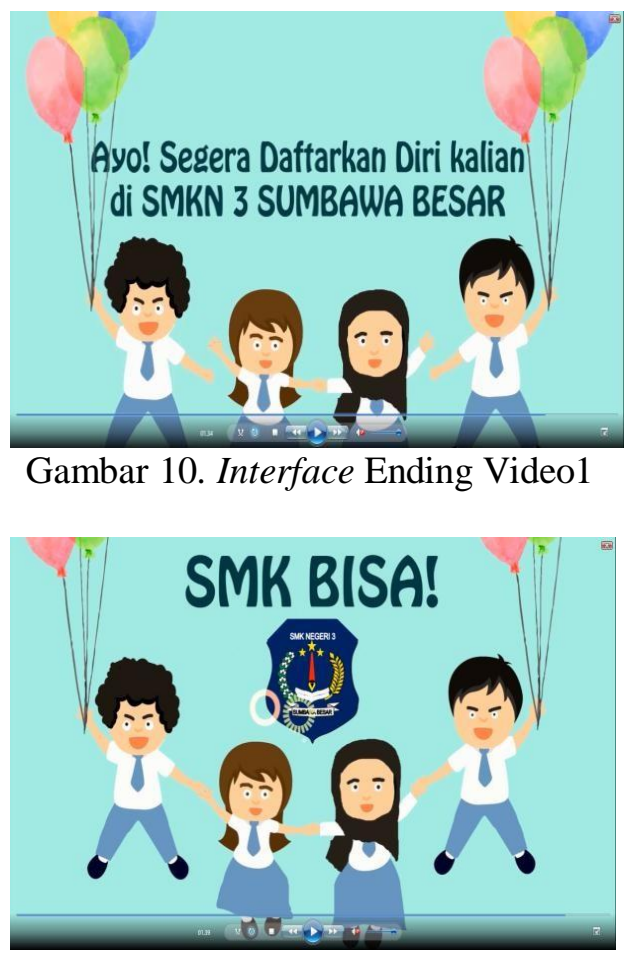

Gambar 11. Interface Ending Video2

\section{Pembahasan}

\section{Uji Coba (Testing)}

Uji coba atau testing dilakukan untuk mengetahui apakah video animasi yang di buat dapat di terima sebagai media promosi SMKN 3 Sumbawa Besar. Pengujian dilakukan oleh betha test atau penguna akhir cara mengisi angket yang akan di berikan ke bagian promosi SMKN 3 Sumbawa Besar.

a) Alpha Test
Alpha test dilakukan langsung oleh pembuat video animasi untuk menguji apakah program yang telah dibuat berjalan dengan benar. Berikut tabel pengujian program :

Tabel 1. Hasil Uji Coba Video Animasi

\begin{tabular}{|c|c|c|c|}
\hline \multirow{2}{*}{ NO } & \multirow{2}{*}{ Visual } & \multicolumn{2}{|c|}{ Berfungsi } \\
\hline & & Ya & Tidak \\
\hline 1 & $\begin{array}{l}\text { Video Animasi } \\
\text { a. Animasi Teks / } \\
\text { Title } \\
\text { b. Animasi Gambar } \\
\text { c. Audio }\end{array}$ & $\begin{array}{l}\sqrt{ } \\
\sqrt{ } \\
\sqrt{ } \\
\sqrt{ }\end{array}$ & \\
\hline
\end{tabular}

b) Betha Test

Betha test dilakukan dengan metode angket dimana responden adalah beberapa pengelola SMKN 3 Sumbawa Besar dan calon siswa dan siswi. Cara mengujinya adalah dengan memperlihatkan video animasi SMKN 3 Sumbawa Besar kepada responden kemudian responden memberikan penilaian pada kuisioner yang dibagikan.

Tujuan dari dilakukannya betha test ini agar penulis dapat mengetahui apakah Video SMKN 3 Sumbawa Besar yang di buat dapat dijadikan media promosi bagi SMKN 3 Sumbawa Besar. Berikut ini hasil metode angket yang diberikan kepada beberapa Guru SMKN 3 Sumbawa Besar yaitu :
a. Bagian Humas
b. Bagian Kesiswaan
c. Siswa dan Siswi SMNKN 3 Sumbawa Besar

Berikut tabel hasil uji coba program kepada pengguna : 
Tabel 2. Hasil Uji Coba Responden dengan

\begin{tabular}{|c|c|c|c|c|c|}
\hline \multirow[b]{2}{*}{ No } & \multirow[b]{2}{*}{ Bahasaan } & \multicolumn{4}{|c|}{ Penilaian } \\
\hline & & SS & $\mathrm{S}$ & KS & TS \\
\hline 1 & Kualitas animasi sudah cukup baik. & 11 & 19 & 0 & 0 \\
\hline 2 & $\begin{array}{l}\text { Informasi yang disampaikan sudah } \\
\text { jelas. }\end{array}$ & 2 & 21 & 7 & 0 \\
\hline 3 & $\begin{array}{l}\text { Penggunaan tokoh dalam video ini } \\
\text { dapat menjadi dava tarik. }\end{array}$ & 10 & 13 & 6 & 1 \\
\hline 4 & $\begin{array}{l}\text { Video ini cukup membantu sebagai } \\
\text { sarana informasi dan promosi. }\end{array}$ & 14 & 15 & 1 & 0 \\
\hline 5 & $\begin{array}{l}\text { Pesan yang disampaikan dalam } \\
\text { video ini mudah dipahami. }\end{array}$ & 6 & 19 & 5 & 0 \\
\hline & TOTAL & $\begin{array}{c}43 \\
29 \%\end{array}$ & $\begin{array}{c}87 \\
58 \%\end{array}$ & $\begin{array}{c}19 \\
12 \%\end{array}$ & $\begin{array}{c}1 \\
1 \%\end{array}$ \\
\hline
\end{tabular}

Siswa SMKN 3 Sumbawa Besar Berdasarkan perhitungan betha test diatas maka di peroleh hasil dari masing-masing kolom penilaian data kuisioner dengan 30 responden, diperoleh sebagai berikut :

1. Bahasan dari kualitas animasi sudah cukup baik diperoleh nilai SS (Sangat Setuju) dari 11 responden, dan nilai S (Setuju) dari 19 responden.

2. Bahasan dari informasi yang disampaikan sudah jelas diperoleh nilai SS (Sangat Setuju) dari 2 responden, nilai S (Setuju) dari 21 responden, dan nilai KS (Kurang Setuju) dari 7 responden.

3. Bahasan dari penggunaan tokoh dalam video ini dapat menjadi daya tarik diperoleh nilai SS (Sangat Setuju) dari 10 responden, nilai $\mathrm{S}$ (Setuju) dari 13 responden, nilai KS (Kurang Setuju) dari 6 responden, dan nilai TS (Tidak Setuju) dari 1 responden.

4. Bahasan dari video ini cukup membantu sebagai sarana informasi dan promosi diperoleh nilai SS (Sangat Setuju) dari 14 responden, nilai $S$ (Setuju) dari 15 responden, dan nilai KS (Kurang Setuju) dari 1 responden.

5. Bahasan dari pesan yang disampaikan dalam video ini mudah dipahami diperoleh
6. nilai SS (Sangat Setuju) dari 6 responden, nilai $S$ (setuju) dari 19 responden, dan nilai KS (Kurang Setuju) dari 5 responden.

Jadi total hasil perhitungan betha test diatas maka di peroleh hasil dari masing-masing kolom penilaian data kuisioner dengan 30 responden, diperoleh 29\% responden memberikan penilaian SS (Sangat Setuju), 58\% responden memberikan penilaian $S$ (Setuju), $12 \%$ responden memberikan penilaian $\mathrm{KS}$ (Kurang Setuju) dan 1\% responden memberikan penilaian TS (Tidak Setuju).

\section{Distribution}

Video promosi distribusikan memelalui berbagai macam yaitu dalam bentuk file, DVD, dan berbagai situs sosial media seperti youtobe, facebook dan Instagram.

a. Penulis mengemas video animasi dua dimensi SMKN 3 Sumbawa Besar dalam bentuk $D V D$.

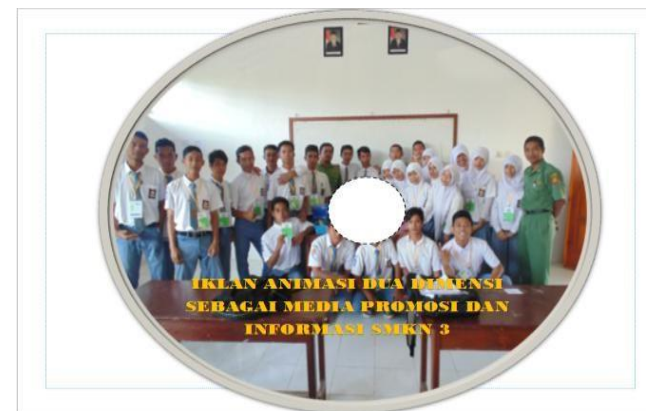

Gambar 12. Distribusi Bentuk DVD

b. Penulis mendistribusikan Video Animasi Dua Dimensi Sebagai Media Promosi SMKN 3 Sumbawa Besar dengan akun penulis diberbagai situs sosial/sosial media seperti youtube, facebook dan instagram format Full HD dengan resolusi 1080 seperti pada gambar dibawah ini :

\section{SIMPULAN DAN SARAN}




\section{Kesimpulan}

Berdasarkan hasil penelitian dan pembahasan dapat diambil kesimpulan yaitu penelitian ini berhasil membuat sebuah video sebagai media promosi SMKN 3 Sumbawa besar dengan konten animasi dua dimensi dan berdasarkan hasil uji coba dari SMKN 3 Sumbawa Besar tersebut dapat disimpulkan bawha $29 \%$ responden

\section{Sran}

Dari paparan pada bab - bab sebelumnya, maka penulis menyadari bawha penelitiani ini masih jauh dari sempurna, sehingga penulis mengemukakan saran sebagai berikut:

1. Penulis merasa informasi yang ada di video ini masih kurang sehingga perlu tambahan informasi.

2. Dalam pembuatan video ini penulis menggabungkang video asli SMKN 3 Sumbawa Besar atas dasar permintaan dari sekolah.

3. Untuk kedepannya video promosi SMKN 3 Sumbawa Besar dapat dikembangkan dalam menampilkan informasi yang lebih rinci mengenai SMKN 3 Sumbawa Besar.

Demikian kesimpulan dan saran dari penulis skripsi ini, dengan harapan dapat bermanfaat menjawab sangat setuju, 58\% menjawab setuju, $12 \%$ menjawab kurang setuju dan $1 \%$ tidak setuju bahwa Video Animasi Dua Dimensi ini mempunyai kualitas yang baik, informasi yang jelas, menjadi daya tarik, dan bisa menjadi sarana promosi dan informasi serta pesan yang disampaikan dalam video ini mudah dipahami oleh pengguna atau calon siswa.

bagi semua pihak, saran yang bersifat membangun sangat diharapkan untuk dapat menyempurnakan penelitian ini.

\section{REFERENSI}

1. Putra, W. (2011). Perancangan animasi promosi iklan. Publikasi, 4. Dipetik Mei 16 2016

2. Binanto, Iwan. (2010). Multimedia DigitalDasar Teori dan Pengembangannya. Yogyakarta: C.V. ANDI OFFSET

3. Akhmad, B., Tamsik U., dan A. Zaenuddin. (2016). Pengaruh Penggunaan Video Pembelajaran Terhadap Peningkatan Hasil Belajar Mapel IPA, 3. Dipetik Juni 2016 